\title{
Acne: What Does Youth Think About It?
}

\section{Akne: Gençler Ne Düşünüyor?}

\author{
Ilyas Erken ${ }^{1}$, Ülkü Yıldız², Melike Eskici ${ }^{3}$, Gizem Limnili ${ }^{4}$, Nilgün Özçakar ${ }^{4}$
}

\begin{abstract}
Objective: Acne vulgaris, a chronic disorder of pilosebaceous units, is common in adolescents. Early detection and appropriate treatment of acne is essential in the prevention of severe acne and scarring, and the consequent adverse psychosocial disabilities resulting from feelings of embarrassment, frustration and poor self-esteem. Emotional issues in young individuals with acne must be identified appropriately. Material and method: This was a cross-sectional survey involving students applied to a University Medical Center. They were administered a questionnaire including socio-demographical properties, general knowledge about acne and Rosenberg Self-Esteem Scale's first ten questions. SPSS 15.0 program was used for statistical analysis and $\mathrm{p}<0.05$ was accepted as statistical significant. Results: Two hundred and forty seven students were included and $63.6 \%$ (n.157) were women. Mean age was $21.40 \pm 2.38$. Majority of the students (99.3\%) had acne but $41.3 \%$ of acne problems had lasted before three months. Acne was defined as an illness by $53.4 \%$ of the students and $38.1 \%$ visited a doctor for acne treatment. Conclusion: Despite the high prevalence of acne, there is still much deficiency of knowledge and wrong beliefs about acne. This indicates that there is a need for education about etiopathogenesis, potential complications and importance of effective treatment for acne.
\end{abstract}

Keywords: Acne, acne perception, adolescence, university students, self-esteem, Rosenberg Self-Esteem Scale

\section{ÖZET}

Amaç: Akne vulgaris, pilosebase birimlerin ergenlerde yaygın olarak görülen kronik bir hastalığıdır. Aknenin erken tanısı ve uygun tedavisi, şiddetli akne ile yara izi oluşumunun utanç, hayal kırıklığı, düşük benlik saygısı duygularından kaynaklanan, olumsuz psikososyal sorunların önlenmesinde önemlidir. Akneli genç bireylerde, duygusal konular, uygun teşhis edilmelidir. Yöntem: Bu çalışma, bir üniversitenin medikososyal hizmetler birimine başvuran öğrencilerin yer aldığı kesitsel bir çalışmadır. Katılımcılara, sosyodemografik özellikler, akne hakkında genel bilgiler ve Rosenberg Benlik Saygısı Ölçeği ilk on sorusunu içeren bir anket uygulanmıştır. Veri analizinde SPSS 15.0 kullanılmış ve $p<0.05$ anlamlı kabul edilmiştir. Bulgular: Çalışmaya 247 öğrenci dâhil edilmiş olup \% 63,6'sı (n=157) kadındır. Yaş ortalaması 21.40 2.38 (Min=18, Maks=32) olan öğrencilerin çoğunluğunda (\%99,3) akne görüldüğü, \%41,3'ünde üç aydan az sürdüğü belirtilmiştir. Öğrencilerin \%53,4'ü akneyi bir hastalık olarak tanımlamış ve \%38,1'i akne tedavisi için doktora başvurmuştur. Sonuç: Üniversite öğrencileri arasında akne görülme sıklığı yüksek olmasına rağmen, akne hakkındaki bilgi düzeyleri düşük bulunmuştur. Konuyla ilgili olarak etiyopatogenez, potansiyel komplikasyonlar ve uygun tedavinin önemi açısından gerekli bilgilendirmenin yarar sağlayabileceği düşünülmektedir.

Anahtar kelimeler: Akne, akne algısı, ergenlik, üniversite öğrencileri, benlik saygısı, Rosenberg Benlik Saygısı Ölçeği

Received / Geliş tarihi: 29.06.2019, Accepted / Kabul tarihi: 10.11.2019

${ }^{1}$ Osmangazi Aile Sağlığı Merkezi, Aile Hekimliği, Eskişehir, Türkiye

${ }^{2}$ Köyceğiz 1 Nolu Merkez Aile Sağlığı Merkezi, Aile Hekimliği, Muğla, Türkiye

${ }^{3}$ Bayramiç Çarşı Aile Sağlı̆̆ 1 Merkezi, Aile Hekimliği, Çanakkale, Türkiye

${ }^{4}$ Dokuz Eylül Üniversitesi, Aile Hekimliği AD, İzmir, Türkiye

*Address for Correspondence / Yazışma Adresi: Gizem Limnili, Dokuz Eylül Üniversitesi Tıp Fakültesi Aile Hekimliği AD, 35340, Balçova-İZMï -

TÜRKIYE, E-mail: gizem.limnili@deu.edu.tr

Erken İ. Yıldız Ü. Eskici M. Limnili G. Özçakar N. Akne: Gençler Ne Düşünüyor?. TJFMPC, 2020;14 (1): 66-71.

DOI: $10.21763 / \mathrm{tjfmpc} .693094$ 


\section{GíRiș}

Akne, en sık görülen deri hastalığıdır ve pilosebase ünitenin multifaktöriyel, kronik yangısı olarak tanımlanmaktadır. Ergenlik dönemine ait ve genel olarak kendini sınırlayan bir hastalık olmasına karşın, yetişkinlik döneminde de yüksek oranda görülmeye devam etmektedir. ${ }^{1}$ Akne patogenezinde rol oynayan dört ana neden bilinmektedir. Bunlar; sebase bezlerde sebum üretimi, Propionibacterium acnes'in foliküler kolonizasyonu, keratinizasyondaki değişiklik ve enflamatuar mediatörlerin deriye salınmasıdır. ${ }^{2,3}$ Akne görülen bireylerde tedavi, hastaya özel olarak lezyonların şiddetine, klinik tabloda belirgin olan lezyonun türüne, hastanın yaşına ve daha önce uygulanmış tedavilere göre planlanmaktadır. Akne tedavisinde kullanılan ilaçlar, gözeneklerin kapanmasını engellemek amaciyla keratin hücrelerinin ve sebum üretiminin azaltılmasını içerenler, mikrobiyosidal ve hormon tedavileri olarak özetlenebilir. ${ }^{4}$

Yapılan çalışmalarda, bireylerin akne algısı ve konuyla ilgili bilgisinin kısıtlı olduğu bildirilmektedir. Akne patogenezi ve tedavisi bilinir olmasına karşın hastaların çoğu doktora ya hiç başvurmamakta ya da geç başvurarak gerekli tedaviyi almaya geç başlamaktadır. ${ }^{5-9}$ Klinik bulgular bireylerde kozmetik yakınmalara neden olduğu kadar, psikolojik sorunlara da yol açmaktadır. Ancak bu durumun yaratacağı duygusal etkinin düzeyini ve şeklini önceden tahmin etmek oldukça güçtür. ${ }^{10,11}$ Yapılan araştırmalarda, akne hastalarının kendilerine güven duyguları daha düşük, sosyal ilişkileri kısıtlı, depresyon, anksiyete skorları yüksek olarak bulunmuştur. ${ }^{12-14}$ Vücudun görünen bölgelerindeki lezyonların ve diğer cilt hastalıklarının yaşam kalitesine olumsuz etkisi ortaya konulmuştur. ${ }^{15}$ Aknenin, kişilik gelişimininin yaşandığı ergenlik döneminde ortaya çıkması, bu hastalığı kişilerin kaygılarının odak noktası haline getirmektedir. $\mathrm{Bu}$ nedenle kişiler arası ilişkilerde, bireyin kendisi ile ilgili değerlendirmelerinde ve günlük performansında etkili olmaktadır. ${ }^{16}$ Aknenin, erken dönemde tanınarak tedavi edilmesi ciddi akne oluşumunu ve akneye bağlı skar oluşumunu engelleyerek psikososyal yan etkileri de azaltabilir. Aknenin yol açtığı psikolojik sorunları araştıran pek çok çalışma olmasına karşın, aknenin kişinin benlik saygısı üzerine olan etkisini araştıran çalışmalar kısıtlıdır. Günümüzde gençlerde beden imajının önemi göz önünde tutulduğunda akneli hastalarda benlik saygısının da araştırılması ön plana çıkmaktadır. $\mathrm{Bu}$ araştırma, gençlerin aknenin patogenezine ilişkin bilgileri, bilgi kaynakları, tedavi seçenekleri ve beklentileri ile benlik saygıları arasındaki ilişkiyi değerlendirmek üzere planlanmıştır.

\section{YÖNTEM:}

Kesitsel tanımlayıcı olarak planlanan araştırmaya, etik kurul ve kurumdan gerekli izinler alındıktan sonra herhangi bir nedenle Mayıs-Haziran 2014 tarihleri arasında, üniversitemizin medikososyal birimi'ne başvuran toplam 310 üniversite öğrencisinden çalışmaya katılmayı kabul eden 247 'si $(\% 79,6)$ alınmıştır. Yüz yüze görüşme yöntemiyle demografik bilgiler, akne ile ilgili sorular sorulmuştur. Ankette ayrıca Rosenberg Benlik Saygısı Ölçeğinin ilk "10" maddesini içeren bir anket uygulanmıştır. Ölçeğin uygulanan ilk 10 maddesi benlik saygısını ölçmeye yöneliktir. Ölçek, ile 0-1 puan yüksek düzeyde benlik saygısı, 2-4 puan orta düzeyde benlik saygısı, 5-6 puan ise düşük düzeyde benlik saygısı olarak değerlendirilmektedir. Ölçekten alınan puanın yükselmesi, benlik saygısı düzeyinin düşmesine işaret etmektedir. Veriler 15.0 SPSS programıla değerlendirilmiş ve $p<0.05$ anlamlı kabul edilmiştir.

\section{BULGULAR:}

Çalışmaya alınan 247 katılımcının $\% 63,6(\mathrm{n}=157)$ 's1 kadın olup, ortalama yaş $21,40 \pm 2,38(\min =18$, mak=32)'dir. Okuduklar1 fakültelere göre değerlendirildiklerinde $\% 29,1(\mathrm{n}=72)$ 'i mühendislik fakültesinde, $\% 44,5(n=110)$ 'i 1. sinıfta öğrenim görmektedir. Katılımciların \%93,9(n=232)'unun aknesi olmuş, $\% 41,3(\mathrm{n}=102)$ 'ünde üç aydan kısa sürdüğü ifade edilmiştir (Tablo 1). Tablo ayrıca katılımcıların akne ile ilgili bilgi ve düşüncelerini göstermektedir. Akne yapan nedenler sorulduğunda \%49,8(n=120)'i hormonlar1, $\% 47,0(n=114)$ '1 $\quad$ beslenmeyi belirtmişlerdir. Akne yapan nedenler olarak ifade edilenlerin tümü açısından her iki cinsiyet arasında anlamlı bir fark bulunmamıştır $(\mathrm{p}>0.05)$. Katılımcıların \%53,4(n=132)'ü akneyi bir hastalık olarak değerlendirdiğini belirtmiş; \%38,1(n=94)'i akne nedeniyle doktora başvurduğunu bildirmiştir. Akne sebebiyle aldıkları tedavi \%56,4(n=53)'ünün beklentilerini kısmen karşılamıştır. Katılımcıların $\% 8,4(n=19)$ 'ü akne varlığının arkadaşlık ilişkilerini ve $\% 7,1(n=16) ' i$ okul ilişkilerini olumsuz etkilediğini bildirmiştir.

Katılımcılara Rosenberg Benlik Saygısı Ölçeği'nin ilk on sorusu uygulanmıştır. Katılımcıların Benlik Saygısı Ölçeği'nden aldıkları puanlara göre $\% 66,8(n=165)$ 'inin benlik saygıs1 yüksek, $\% 32,8(n=81)$ 'inin orta ve $\% 0,4(n=1)$ 'ünün düşük bulunmuştur. Yapılan analizlerde cinsiyet, akneyi bir hastalık olarak kabul etme, doktora başvurma, uzun süreli tedavi alma durumu ile benlik saygısı arasında istatistiksel olarak anlamlı fark bulunmamıştır ( $p=0,38, p=0,26, p=0,90, p=0,59$ sırasıyla). Aknenin arkadaşlık ilişkilerini olumsuz etkilemesi ve Rosenberg Benlik Algısı Ölçeği 
puanları arasında istatistiksel olarak anlamlı bir fark bulunurken; okul ilişkilerini olumsuz etkileme ve ölçek puanları arasında anlamlı bir fark bulunamamıştır ( $\mathrm{p}=0,02, \mathrm{p}=0,17$ sırasıla) (Tablo2).

\section{TARTIŞMA:}

Akne vulgaris, sosyal becerilerin ve bireyler arası ilişkilerinin en çok geliştiği adölesan ve genç erişkinlik döneminde görülen en yaygın deri hastalığıdır. ${ }^{17,18}$ Bu çalışmada; daha önce üniversite öğrencileri ile yapılan çalışmalara benzer şekilde akneyle karşılaşmı̧s olan öğrenciler çoğunluktadır. ${ }^{6,9,11}$ Öğrencilere akneye nelerin sebep olduğu sorulduğunda cevap olarak en sik hormonları; akneyi en çok şiddetlendiren neden olarak da stresi göstermişlerdir. Androjenlerin akne oluşumunda rolü olduğu bilinmektedir ancak akne oluşumunda beslenmenin önemi ile ilgili çalışmaların sonuçlarında, farklı ifadelere rastlanmakta ve bu konuda daha fazla çalışmaya ihtiyaç duyulduğu belirtilmektedir. ${ }^{19-22}$ Literatürde sıklık sıralaması değişmekle birlikte, çalışmamıza benzer şekilde toplumda akne yaptığına inanılan sebepler arasında hormonlar, beslenme, cilt hijyeni, genetik ve stres gösterilmiştir. Bu nedenlere ilişkin bilgilerin bazılarının geçerliliği hala tartışılmaktadır ancak bu duruma ve siklik siralamasının değişmesine toplum kültürünün neden olduğu belirtilmektedir. ${ }^{20,23}$ Katılımciların yarısı akne oluşumunu hastalık olarak kabul etmekle birlikte bu sebeple doktora başvuruları kısitlıdır. Bu durum akneyi hormon, beslenme, hijyen gibi değişik faktörlere bağlayarak normalleştirilmeleri ile açıklanabilir. Yapılan diğer çalışmalarda da akne nedenleri arasında ifade edilenler benzer bulunmuştur. ${ }^{6,7,9,11}$ Katılımcıların çoğu aknenin tedavisi olduğunu düşünmekte ve tedavi süresinin bir ay ile altı ay arasında değiştiğini belirtmektedir. Bunun yanı sıra tedavi alanların da tedavi süresi kısadır. Bu durum, tedavi seçenekleri ve süresi ile ilgili farkındalığının yeterli olmadığını düşündürmektedir. Ülkemizde yapılan bir çalışmada benzer sonuçlar bulunmuştur. ${ }^{24}$ Tedavi için kullanıldığı en çok bilinen ilaçlar cilt temizleme ürünleridir. Bunu hormonlar ve antibiyotikler izlemektedir. Kozmetik olarak cilt temizleme ürünleri reklamlar aracılığıyla bu yaş grubuna daha çok tanıtıldığından, en çok bilinen tedavi seçeneği bu olabilir. Gençlerin akneye ilișkin farkındalıkları, tıbbi yardım alma ve tedavi uygulamalarına uyum gibi konularda önemli rol oynamaktadır. Akne tedavisine erken dönemde başlanması, uygun tedavinin, uygun süre uygulanması postinflamatuar hiperpigmentasyon veya akneye bağlı skar oluşumu gibi komplikasyonların engellenmesi açısından önemlidir.

Yapılan çalışmalarda akneye bağlı skar oluşumunun kişinin psikososyal durumunu olumsuz etkilediği görülmüştür. ${ }^{3,8}$ Gençler kimlik iletişiminin ve diğerleri tarafından beğenilmenin bir ifadesi olarak görünümleri ile daha fazla ilgilidirler. Yine de akne ile anksiyete-depresyon arasındaki ilişkiyi sorgulayan çalışmaların sonuçlarında bir görüş birliği sağlanamamıştır. Akne vulgarisli hastalarda, anksiyetenin arttığına dair çalışmalar olduğu gibi böyle bir ilişkinin olmadığını bildiren çalışmalar da mevcuttur. ${ }^{25,26} \mathrm{Bu}$ durumu destekleyen çalışmalarda psikiyatrik belirtilerle, hastalık şiddeti arasında bir

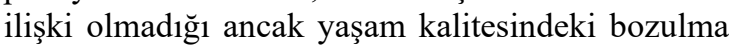
ile ilişkili olduğunu vurgulanmıştır. ${ }^{23,27}$ Bununla birlikte, çalışmaların yapıldığı toplumlar arasındaki farklılıkların sonuçları etkileyebileceği de düşünülmektedir. ${ }^{28}$ Çalışmamızda gençlerin anlık benlik saygıları yüksektir. Akneyi bir hastalık olarak kabul edenler, uzun süreli tedavi alanlar ile benlik saygısı arasında istatistiksel olarak anlamlı fark bulunmamıştır. Öğrencilere aknenin arkadaşlık ilişkileri üzerine olumsuz etkileri soruluğunda, bu ilişkiler ile benlik saygısı ölçek puanları arasında istatistiksel olarak anlamlı fark bulunmuştur. Buna karşın aknenin okul içi ilişkileri olumsuz etkilemesi ile benlik saygısı ölçek puanları arasında anlamlı istatistiksel fark bulunmamıştır. Yapılan bazı çalışmalarda, akne varlığının arkadaşlık ve ikili ilişkileri, okul başarısını olumsuz yönde etkilediğine dair sonuçlar bulunmaktadır ${ }^{29}$. Çalışmamamızda bulunan farklılıklar, çalışmada yer alan katılımcıların anlık akne şiddetlerinin öznel olarak değerlendirmemiş olmasından kaynaklanabileceği gibi, akneyi yaş döneminin olağan bir parçası olarak kabul etmelerinden de kaynaklanıyor olabilir. Aynı zamanda benlik saygısının gelişimi içinde sosyal yaşamın, kişilerarası ilişkilerin, iş ve okul yaşamı gibi birçok alanın da payı vardır ve kişinin sorunlarla mücadele gücünün, hastalığı yorumlama şeklinin ve hastalığın süresinin bu konuda değişiklik yaratabileceği düşünülmektedir. Tüm bu nedenlerle, aknenin s1klıkla en yoğun sosyal ve fiziksel değişikliklerin görüldüğü, kimlik gelişiminin yaşandığı ve kalıcı psikolojik sekellerin gelişebileceği ergenlik döneminde ortaya çıkması $\mathrm{da}$, bu komplikasyonların önlenmesinin önemini göstermektedir.

\section{SONUÇ:}

Akne, ergenlik döneminde başlayıp ömür boyu sürebilen bir durumdur. Farkında olma ve bir uzmandan yardım alma, fiziksel, sosyal, psikolojik yönlerden etki ve sonuçlarını azaltacaktır. Gençlerde akne ile ilgili olarak etiyopatogenez, potansiyel komplikasyonlar ve uygun tedavinin önemi açısından gerekli bilgilendirmenin yarar sağlayabileceği düşünülmektedir. 


\section{KAYNAKLAR}

1. Dawson AL, Dellavalle RP. Acne vulgaris. BMJ 2013;346:f2634.

2. Thiboutot D, Gollnick H, Bettoli V, Dréno B, Kang S, Leyden JJ et al. New insights into the management of acne: an update from the Global Alliance to Improve Outcomes in Acnegroup. J Am Acad Dermatol. 2009 May;60(5 Suppl):150.

3. Güngör E. Akne. Turk J Dermatol 2012; 6: 13849.

4. Botros PA, Tsai G, Pujalte GGA. Evaluation and Management of Acne. Primary Care: Clinics in Office Practice 2015;42(4):465-471.

5. Tan JKL, Vasey K, Fung KY. Beliefs and perceptions of patients with acne. J Am Acad Dermatol 2001;44(3):439-445.

6. Uslu G, Sendur N, Uslu M, Savk E, Karaman G, Eskin M. Acne: prevalence, perceptions and effects on psychological health among adolescents in Aydin, Turkey. Journal of the European Academy of Dermatology and Venereology, 2008;22(4):462-469.

7. Smithard A, Glazebrook C, Williams HC. Acne prevalence, knowledge about acne and psychological morbidity in mid-adolescence: a community-based study. Br J Dermatol 2001; 145(2): 274-279.

8. Yahya H. Acne vulgaris in Nigerian adolescents-prevelance, severity, beliefs, perceptions, and practices. Int J Dermatol 2009; 48: 498-505.

9. Al Robaee AA. Prevalence, knowledge, beliefs and psychosocial impact of acne in university students in Central Saudi Arabia. Saudi Med J 2005; 26:1958-61.

10. Fried RG, Wechsler A. Psychological problems in the acne patient. Dermatologic Therapy 2006; 19: 237-240.

11. Su P, Chen Wee Aw D, Lee SH, Han Sim Toh MP. Beliefs, perceptions and psychosocial impact of acne amongst Singaporean students in tertiary institutions. J Dtsch Dermatol Ges. 2015;13(3):227-33.

12. Aktan Ş, Özmen E, Şanlı B. Anxiety, depression, and nature of acne vulgaris in adolescents. Int J Dermatol 2000;39: 354-7.

13. Behnam B, Taheri R, Ghorbani R, Allameh P. Psychological Impairments in the Patients with Acne. Indian Journal of Dermatology 2013; 58(1):26-9.

14. Yolaç Yarpuz A, Demirci Saadet E, Erdi Sanli $\mathrm{H}$, Devrimci Ozgüven $\mathrm{H}$. Akne Vulgaris Hastalarında Sosyal Kaygı Düzeyi ve Bunun Klinik Değişkenler İle İlişkisi. Turk Psikiyatri Derg 2008;19(1):29-37.
15. Gurel MS, Yanik M, Simsek Z, Kati M, Karaman A. Quality of life instrument for Turkish people with skin diseases. Int $\mathrm{J}$ Dermatol 2005;44(11):933-8.

16. Hanna S, Sharma J, Klotz J. Acne vulgaris: more than skin deep. Dermatol Online J 2003;9(3):8.

17. Williams HC, Dellavalle RP, Garner S. Acne vulgaris. Lancet 2012; 379: 361-72.

18. Tan JK, Bhate K. A global perspective on the epidemiology of acne. Br J Dermatol. 2015;172 (1):3-12. doi: 10.1111/bjd.13462.

19. Rzany B, Kahl C. Epidemiology of acne vulgaris. JDDG 2006; 4:8-9.

20. Magin P, Adams J, Heading G, Pond D, Smith W. The causes of acne: a qualitative study of patient perceptions of acne causation and their implication for acne care. Dermatol Nurs 2006; 18: 344-349.

21. Veith WB1, Silverberg NB. The association of acne vulgaris with diet. Cutis 2011 Aug;88(2):84-91.

22. Davidovici BB. and Wolf $\mathrm{R}$. The role of diet in acne: facts and controversies, Clin Dermatol 2010;28(1):12-6. 10.1016/j.clindermatol.2009.03.010.

23. Yazici K, Baz K, Yazici AE, Kokturk A, Tot S, Demirseren D et al. Disease -specific Quality of life is associated with anxiety and depression in patients with acne. J Eur Acad Dermatol Venereol 2004; 18: 435-9.

24. Kaptanoglu AF, Çalısır ZE, Akdur R. Türkiye'deki genç popülasyonda akneye ilişkin inanışlar, algılamalar ve tutumlar. Near East Medical Journal 2011;1(1):7-13.

25. Kaymak Y, Ulutaş I, Taner E, Bakir B, Simşek I. Body image satisfaction and anxiety of a Turkish sample of university students with skin diseases. Psychol Rep. 2007;100(2):499-508.

26. Shahzad N, Nasir J, Ikram U, Asmaa-ul-Haque, Qadir A, Sohail MA. Frequency and psychosocial impact of acne on university and college students. J Coll Physicians Surg Pak. 2011;21(7):442-3. doi: 07.2011/JCPSP.442443.

27. Çelik T, Akman A, Karaman T, Başaran E, Yllmaz E. Alopesi Areata ve Akne Vulgarisin Ruhsal Durum Üzerine Etkileri. Turk J Dermatol 2010; 4: 4-8.

28. Magin P, Pond C, Smith W, Goode S. Acne's relationship with psychiatric and psychological morbidity: results of a school-based cohort study of adolescents. J Eur Acad Dermatol Venereol 2010; 24: 58-64.

29. Nguyen CM, Beroukhim K, Danesh MJ, Babikian A, Koo J, Leon A. The psychosocial impact of acne, vitiligo, and psoriasis: a review Clinical, Cosmetic and Investigational Dermatology 2016:9 383-392. 


\begin{tabular}{|c|c|c|c|}
\hline & & $\mathrm{n}$ & Yüzde (\%) \\
\hline \multirow{2}{*}{ Cinsiyet } & Kadın & 157 & 63,6 \\
\hline & Erkek & 90 & 36,4 \\
\hline \multirow{7}{*}{ Fakülte } & Mühendislik & 72 & 29,1 \\
\hline & Hemşirelik & 53 & 21,5 \\
\hline & İşletme-iktisat & 55 & 22,3 \\
\hline & Fen edebiyat & 32 & 13,0 \\
\hline & Denizcilik & 13 & 5,3 \\
\hline & Mimarlık & 7 & 2,8 \\
\hline & Diğer & 15 & 6,0 \\
\hline \multirow{7}{*}{ Sinif } & Hazırlık & 17 & 6,9 \\
\hline & 1 & 110 & 44,5 \\
\hline & 2 & 39 & 15,8 \\
\hline & 3 & 44 & 17,8 \\
\hline & 4 & 31 & 12,6 \\
\hline & Yüksek lisans & 2 & 0,8 \\
\hline & Doktora & 3 & 1,2 \\
\hline \multirow{2}{*}{$\begin{array}{l}\text { Hayatınızın herhangi bir döneminde } \\
\text { akneniz oldu mu? }\end{array}$} & Evet & 232 & 93,9 \\
\hline & Hayır & 15 & 6,1 \\
\hline \multirow{4}{*}{ Akneniz ne kadar süre devam etti? } & $<3$ ay & 102 & 41,3 \\
\hline & $3-6$ ay & 28 & 11,3 \\
\hline & $7-12$ ay & 26 & 10,5 \\
\hline & $>1$ y1l & 91 & 36,9 \\
\hline \multirow{7}{*}{$\begin{array}{l}\text { Akne oluşumuna neden olduğu ifade edilen } \\
\text { faktörler hangileridir? }\end{array}$} & Hormonlar & 120 & 48,6 \\
\hline & Beslenme & 114 & 46,2 \\
\hline & Cilt hijyeni & 47 & 19,0 \\
\hline & Genetik & 39 & 15,8 \\
\hline & Enfeksiyon & 13 & 5,3 \\
\hline & Stres & 4 & 1,6 \\
\hline & Diğer & 31 & 12,5 \\
\hline \multirow{9}{*}{$\begin{array}{l}\text { Akneyi şiddetlendirdiği } \quad \text { düşünülen } \\
\text { durumlar nelerdir? }\end{array}$} & Stres & 170 & 68,8 \\
\hline & Kizartma yemek & 125 & 50,6 \\
\hline & Kozmetik ürünler & 60 & 24,3 \\
\hline & Çikolata yemek & 59 & 23,9 \\
\hline & Cildin kirli olması & 56 & 22,7 \\
\hline & Uykusuzluk & 35 & 14,2 \\
\hline & Beslenme & 26 & 10,5 \\
\hline & Egzersiz & 2 & 0,8 \\
\hline & Diğer & 11 & 4,4 \\
\hline \multirow{2}{*}{$\begin{array}{l}\text { Akne bir hastalık olarak kabul edilebilir } \\
\text { mi? }\end{array}$} & Evet & 132 & 53,4 \\
\hline & Hayır & 115 & 46,6 \\
\hline \multirow[t]{3}{*}{ Aknenin tıbbi tedavisi var mıdır? } & Evet & 233 & 94,3 \\
\hline & Hayır & 13 & 5,3 \\
\hline & Bilmiyorum & 1 & 0,4 \\
\hline \multirow{2}{*}{$\begin{array}{l}\text { Akne tedavisinde kullanılacak ilaçlar } \\
\text { hangileridir? }\end{array}$} & Cilt temizleme ürünleri & 213 & 86,2 \\
\hline & Topikal tedaviler & 29 & 11,7 \\
\hline
\end{tabular}




\begin{tabular}{|l|r|c|c|}
\hline \multirow{4}{*}{} & Hormonlar & 96 & 38,9 \\
\cline { 2 - 4 } & Kimyasal peeling & 76 & 30,8 \\
\cline { 2 - 4 } & İzoretionin & 8 & 3,2 \\
\cline { 2 - 4 } & Antibiyotik & 96 & 38,9 \\
\hline Akne tedavisi gerekli midir? & Evet & 210 & 85,8 \\
\hline Aknenin tedavi süresi ne kadar olmalıdır? & Hayır & 35 & 14,2 \\
\cline { 2 - 4 } & $<4$ hafta & 78 & 33,3 \\
\cline { 2 - 4 } & $1-6$ ay & 117 & 50,0 \\
\cline { 2 - 4 } & $>6$ ay & 39 & 11,4 \\
\cline { 2 - 4 } & Fikrim yok & 13 & 5,3 \\
\hline \multirow{2}{*}{$\begin{array}{l}\text { Daha önce hiç akne nedeniyle doktora } \\
\text { başvurdunuz mu? }\end{array}$} & Evet & 94 & 38,1 \\
\hline \multirow{2}{*}{$\begin{array}{l}\text { Akne tedavisi için uyguladığınız reçeteli ya } \\
\text { da reçetesiz tedavinin süresi }\end{array}$} & Hayır & 153 & 61.9 \\
\cline { 2 - 4 } & $<4$ hafta & 23 & 31,6 \\
\cline { 2 - 4 } & $1-6$ ay & 37 & 50,6 \\
\hline Rosenberg Benlik Saygısı Ölçeği puanları & $>6$ ay & 13 & 17,8 \\
\cline { 2 - 4 } & Yüksek & 165 & 66,8 \\
\cline { 2 - 4 } & Orta & 81 & 32,8 \\
\cline { 2 - 4 } & Düşük & 1 & 0,4 \\
\hline
\end{tabular}

\begin{tabular}{|c|c|c|c|c|}
\hline & & Rosenberg & yg1s1 Ölçeği puanları & \\
\hline & & Yüksek & Orta ve Düşük & $\mathrm{p}$ \\
\hline \multirow[t]{2}{*}{ Cinsiyet } & Kadın & $104(66,2)$ & $53(33,8)$ & \multirow{2}{*}{0,38} \\
\hline & Erkek & $61(67,8)$ & $29(32,2)$ & \\
\hline \multirow{2}{*}{$\begin{array}{l}\text { Akne bir hastalık olarak kabul } \\
\text { edilebilir mi? }\end{array}$} & Evet & $83(62,9)$ & $49(37,1)$ & \multirow{2}{*}{0,26} \\
\hline & Hayır & $82(71,3)$ & \begin{tabular}{|l|}
$33(28,7)$ \\
\end{tabular} & \\
\hline \multirow{2}{*}{$\begin{array}{l}\text { Hayatınızın herhangi bir döneminde } \\
\text { akneniz oldu mu? }\end{array}$} & Evet & $153(65,9)$ & \begin{tabular}{|l|}
$79(34,1)$ \\
\end{tabular} & \multirow{2}{*}{0,52} \\
\hline & Hayır & $12(80,0)$ & $3(20,0)$ & \\
\hline \multirow{2}{*}{$\begin{array}{l}\text { Daha önce hiç akne nedeniyle } \\
\text { doktora başvurdunuz mu?* }\end{array}$} & Evet & $68(72,3)$ & $26(27,7)$ & \multirow{2}{*}{0,90} \\
\hline & Hayır & $85(61,6)$ & $53(38,4)$ & \\
\hline \multirow{3}{*}{$\begin{array}{l}\text { Akne tedavisi için uyguladığınız } \\
\text { reçeteli ya da reçetesiz tedavinin } \\
\text { süresi* }\end{array}$} & $<4$ hafta & $48(61,5)$ & $30(38,5)$ & \multirow{3}{*}{0,59} \\
\hline & $1-6$ ay & $76(68,5)$ & $35(31,5)$ & \\
\hline & $>6$ ay & $29(67,4)$ & $14(32,6)$ & \\
\hline \multirow{3}{*}{$\begin{array}{ll}\text { Akne } & \text { sebebiyle uyguladığınız } \\
\text { tedavi } & \text { beklentilerinizi karşılladı } \\
\text { mı** } & \end{array}$} & Hiç & $13(72,2)$ & $5(27,8)$ & \multirow{3}{*}{0,98} \\
\hline & Kismen & $38(71,7)$ & \begin{tabular}{|l|}
$15(28,3)$ \\
\end{tabular} & \\
\hline & Tamamen & $17(73,9)$ & $6(26,1)$ & \\
\hline \multirow{2}{*}{$\begin{array}{l}\text { Akne arkadaşlik } \\
\text { olumsuz etkiledi mi?* }\end{array}$} & Evet & $8(42,1)$ & $11(57,9)$ & \multirow[b]{2}{*}{$\mathbf{0 , 0 2}$} \\
\hline & Hayır & $145(68,1)$ & $68(31,9)$ & \\
\hline \multirow{2}{*}{$\begin{array}{l}\text { Akne okul içi ilişkilerinizi olumsuz } \\
\text { etkiledi mi?*}\end{array}$} & Evet & $8(50,0)$ & $8(50,0)$ & \multirow[b]{2}{*}{0,17} \\
\hline & Hayır & $145(67,1)$ & $71(312,9)$ & \\
\hline
\end{tabular}

